DOI: $10.47743 /$ jss-2021-67-4-15

\title{
Uberizarea dreptului - pericol sau oportunitate pentru profesiile juridice liberale?
}

\section{Uberization of Law - Danger or Opportunity for the Liberal Legal Professions?}

\section{Cătălin Boacnă ${ }^{1}$}

Rezumat: Termenul de „uberizare” a devenit prezent în limbajul uzual al ultimilor ani, odată cu extinderea celebrei firme americane de ride-sharing. Principiul de bază este acela că o aplicaţie informatică instalată pe telefonul mobil poate crea legătura dintre un conducător auto independent şi un client care evită serviciile de taximetrie. Criza sanitară provocată de coronavirus a accentuat uberizarea unor domenii precum piaţa muncii, medicină, IT etc. În acest context, apreciez că termenul poate fi folosit în mod adecvat şi în ceea ce priveşte dreptul. Există deja platforme care oferă servicii juridice online sau intermediază legătura dintre client şi avocat. De asemenea, unele softuri legislative pot înlocui sfaturile juridice ale unui avocat sau pot prevedea rezultatul unui proces prin folosirea unor algoritmi. În acest context, uberizarea dreptului reprezintă un pericol sau o oportunitate pentru contractul de asistenţă juridică definit de Legea nr. 51/1995 privind organizarea şi exercitarea profesiei de avocat?

Cuvinte-cheie: uberizarea dreptului; contractul de asistenţă juridică; digitalizare; platforme juridice

\begin{abstract}
The term uberization has become present in the usual language of recent years, with the expansion of the famous american ride-sharing company. The basic principle is that an application installed on the mobile phone can create the connection between an independent driver and a customer who avoids taxi services. The health crisis caused by coronavirus has accentuated the uberization of areas such as the labor market, medicine, IT etc. In this context, I belive that the term can also be used appropriately in terms of law. There are already platforms that offer legal services online or mediate the connection between the client and the lawyer. Also, some legislative software can replace the legal advice of a lawyer or can predict the outcome of a lawsuit by using algorithms. In this context, does the uberisation of law represent a danger or an opportunity for the legal aid contract defined by Law no. 51/1995 on the organization and exercise of the lawyer profession?
\end{abstract}

Keywords: uberization of law; legal aid contract; digitization; legal platforms

${ }^{1}$ Doctorand, Facultatea de Drept, Universitatea „Alexandru Ioan Cuza” din Iași, e-mail: catalin_boacna@yahoo.com. 


\section{Introducere}

Modul de funcţionare a platformei americane de ride-sharing ${ }^{2}$ Uber a dat naştere unor controverse intense încă din momentul lansării ${ }^{3}$, atât din punct de vedere al modelului de afacere, cât şi din punct de vedere juridic. Criticii companiei susţin că în jurul acestei platforme a fost construită o adevărată „cultură a ilegalităţii" , modelul de afaceri bazându-se pe încălcarea legii la nivel global, nu doar în SUA. Pe de altă parte, admiratorii susţin, printre altele, că a revitalizat economia ${ }^{5}$ sau că a adus inovaţii tehnologice, care au schimbat soarta serviciilor tradiţionale, nu doar cele din domeniul taximetriei ${ }^{6}$. În acest context, a apărut termenul „uberizare”, un neologism care descrie „actul sau procesul de schimbare a pieței pentru un serviciu prin introducerea unui mod diferit de cumpărare sau utilizare a acestuia, în special folosind tehnologia mobilă"7 sau, mai clar, se referă la „oferirea de servicii directe prin intermediul unei aplicaţii mobile”. Practic, astăzi, în vorbirea uzuală, termenul „uberizare” nu se mai referă doar la conduita unui utilizator al aplicaţiei „Uber” de a căuta o maşină disponibilă care să-l ducă din punctul A în punctul B, ci se referă la un fenomen social care a cuprins toate domeniile esenţiale, de la economie până la medicină, muzică, turism, piaţa muncii, educaţie, sau chiar domeniul juridic. Uberizarea reprezintă un adevărat fenomen social, iar dreptul este obligat să aibă o reacţie. Cea mai clară reacţie a fost aceea că legislaţiile naţionale şi-au schimbat treptat perspectiva şi au introdus în cotidian inovaţiile tehnologice bazate pe modelul platformei americane de ride-sharing.

\section{Uberizarea dreptului}

„Uberizarea dreptului” este o sintagmă pe care încă nu am regăsit-o în limba română, deşi este deja prezentă, de exemplu, în limbajul juridic din Franţa ${ }^{9}$. Din punctul meu de vedere, termenul de uberizare, folosit pentru a descrie tehnologizarea domeniului juridic trebuie analizat în strânsă legătură cu noţiunea

2 [Online] la https://en.wikipedia.org/wiki/Uber, accesat 10.12.2021.

3 [Online] la https://www.forbes.com/sites/ellenhuet/2014/12/11/ubers-globalexpansion/?sh=8d52806550a7, accesat 10.12.2021.

4 [Online] la https://hbr.org/2017/06/uber-cant-be-fixed-its-time-for-regulators-toshut-it-down, accesat 10.12.2021.

5 [Online] la https://www.theatlantic.com/technology/archive/2019/03/whathappened-uber-x-companies/584236/, accesat 10.12.2021.

6 [Online] la https://digital.hbs.edu/platform-digit/submission/uber-vs-taxi/, accesat 10.12.2021.

7 [Online] la https://dictionary.cambridge.org/dictionary/english/uberization, accesat 10.12.2021.

8 [Online] la https://www.cyberdefinitions.com/definitions/UBERIZATION.html, accesat 10.12.2021.

9 [Online] la https://www.lemonde.fr/idees/article/2015/06/19/vers-une-uberisationdu-droit_4658065_3232.html, accesat 10.12.2021. 
de dematerializare a dreptului ${ }^{10}$ sau dematerializarea procesului judiciar ${ }^{11}$. Definirea dematerializării este mai poetică în dicţionarul explicativ al limbii franceze ${ }^{12}$ decât cea din limba română, însă esenţa este aceeaşi: „dematerializarea” se defineşte ca fiind acţiunea de a elimina ceea ce este material pentru a rămâne doar partea imaterială ${ }^{13}$. Evoluţia tehnologică, dar mai ales modalitatea în care algoritmii vor controla procesul judiciar şi vor elimina partea materială, pare a fi o prioritate atât pentru politica globală a Uniunii Europene ${ }^{14}$ cât şi pentru legislaţia naţională a statelor europene ${ }^{15}$. Astfel, uberizarea dreptului nu va reprezenta doar un mecanism de utilizare a unei aplicaţii informatice pentru a găsi un avocat potrivit pentru un anumit domeniu, pentru a căuta legi, contracte, sau pentru a depune o acţiune la instanţa de judecată, ci va putea reprezenta un mijloc prin care un justiţiabil poate afla verdictul potenţial al unui anumit dosar. Practic, algoritmii vor putea previziona hotărârea judecătorului, iar părţile litigiului respectiv îşi vor putea face aşteptări realiste de la actul de justiţie. Uberizarea dreptului se va realiza în mod treptat, chiar şi forţat ${ }^{16}$, cu opoziţie din partea profesioniştilor, în toate sistemele juridice ale ţărilor dezvoltate şi va schimba radical procesul judiciar tradiţional ${ }^{17}$, având în vedere tocmai experienţa trăită în ceea ce priveşte intrarea pe piaţa mondială a companiei Uber. Deşi în realitate compania oferă servicii specifice taximetriei ${ }^{18}$, iar şoferii independenţi care folosesc aplicaţia sunt în

\footnotetext{
${ }^{10}$ M. Dochy, La dématérialisation des actes du procès civil, Volumul 202, pg. 3, Editura Dalloz, Paris, 2021.

11 Această noțiune apare Opinia Nr.(2011)14 a CCJE - „Justiţia şi Tehnologiile Informatice (IT)”, Adoptată de CCJE în cadrul celei de a 12-a sesiuni plenare, Strasbourg, 79 Noiembrie 2011.

12 "réduire en esprit" - É. Littré, Dictionnaire de la langue française - vb Dématérialiser vs DEX - Dematerializa dematerializez, vb. I. Tranz. și refl. A face să piardă sau a pierde caracteristicile materiei sau chiar materia. [Pr.: -ri-a-] - Din fr. dématérialiser.

${ }^{13}$ C. Rocayaura, Réflexions sur la dématérialisation de la procédure pénale, thèse, Montpellier 1, 2013, no 3.

${ }^{14}$ Carte albă privind inteligența artificială - O abordare europeană axată pe excelență și incredere, Bruxelles, 19.2.2020. Este vorba de un proiect de regulament prezentat la data de 21 aprilie 2021 de Comisia Europeneană, fiind considerat ca fiind prima propunere din lume pentru un cadru legal în ceea ce privește Inteligența Artificială (IA).

${ }^{15}$ Cu ocazia Summit-ului, despre inteligență artificială, martie 2018, Paris, președintele Franței a anunțat strategia națională de cercetare în inteligență artificială, fiind anunțate inclusiv schimbări legislative în acest sens.

${ }^{16}$ N. Fricero, Demande en justice et nouvelles technologies : aspects procéduraux, în Les avocats dans le monde numérique : qu'en est-il aujourd'hui ?, Procédures, nr 10, 2014, dosar 47.

${ }^{17}$ C. Chainais, F. Ferrand, L. Mayer, S. Guinchard, Procédure civile : droit interne européen du procès civil, Editura Dalloz, colecția Précis Dalloz, ediția 34, Paris, 2018, pg. 947: "La dématérialisation des procédures entraîne un bouleversement de nos habitudes et envahit peu à peu toute la vie judiciaire”.

${ }^{18}$ Analiza modului în care funcționează compania Uber a fost realizată de către Curtea de Justiție a Uniunii Europene în Cauza C-434/15 Asociación Profesional Elite Taxi împotriva Uber Systems Spain SL, pronunțată la data de 20 decembrie 2017.
} 
realitate angajaţii Uber ${ }^{19}$, politica de expansiune a fost aceea că oferă servicii specifice domeniului IT punând la dispoziţia utilizatorilor o simplă aplicaţie prin care clienţii îşi pot găsi o maşină, iar conducătorii auto îşi pot găsi clienţi. Pe acelaşi raţionament, în viitorul apropiat, aplicaţiile informatice nu vor oferi doar o intermediere între profesioniştii dreptului şi clienţi, ci vor putea oferi chiar răspunsul la problemele juridice pe care le are clientul respectiv. În ultimii ani există destul de multe exemple concrete prin care statele europene au încercat să digitalizeze inclusiv rolul concret al judecătorului, exemplul cel mai notoriu fiind cel al Estoniei - un program informatic ce judecă litigiile civile cu valoarea de până în $6400 \mathrm{Euro}^{20}$.

După cum am arătat, criza sanitară provocată de coronavirus a accentuat uberizarea unei game largi de domenii. Aş da ca exemplu piaţa muncii, acolo unde ştim cu toţii că există anumite reguli foarte stricte în ceea ce priveşte programul de lucru, forma contractului de muncă (care trebuie înregistrată la Inspectoratul Teritorial de Muncă), durata contractului, sarcinile de serviciu, fişa postului etc. Odată cu dezvoltarea aplicaţiilor informatice, ajungem în situaţia în care o platformă online poate genera nu doar oferte de muncă şi cereri din partea celor care caută, ci poate reprezenta activitatea în sine ${ }^{21}$. Uberizarea muncii a început cel mai clar în domeniul IT, unde există platforme prin intermediul cărora se pun la dispoziţia utilizatorilor oferte de lucru sau utilizatorii pun la dispoziţia angajatului produsul muncii lor. În domeniul turismului, lucrurile sunt şi mai clare pentru că acolo există platforme de tipul booking.com (companie înfiinţată în anul 1996 în Olanda), care pun la dispoziţia turiştilor locuri de cazare, iar unităţile de cazare îşi găsesc clienţii. Acelaşi principiu îl regăsim şi în domeniul artistic sau muzical. Nu mai suntem nevoiţi să cumpăram un disc de vinil pentru a asculta o melodie veche, ci o găsim pe diferite platforme. Filmele nu mai rulează doar în cinema sau la TV, ci avem la dispoziţie platforme de streaming care facilitează activităţile noastre recreative. De asemenea, putem găsi şi medici pe internet, care mai nou oferă consultaţii medicale de la distanţă. În acelaşi timp, au apărut inclusiv aplicaţii informatice care pot da, cu precizie maximă, diagnostice medicale.

\section{Uberizarea în raport cu profesiile liberale-avocatura}

Firmele de taxi sunt în pericol din cauza Uber, sistemul bancar este ameninţat de dezvoltarea criptomonedelor, retailerii au probleme serioase din cauza

${ }^{19}$ Intervenția instanțelor de judecată din majoritatea statelor Europene au cosiderat că şoferii care folosesc aplicaţia sunt, în concret, angajații Uber, cu toate drepturile și obligațiile care decurg din acest statut.

De exemplu, [Online] la https://www.lepoint.fr/justice/le-lien-entre-uber-et-unchauffeur-requalifie-en-contrat-de-travail-21-05-2021-2427556_2386.php, accesat 10.12.2021.

20 [Online] la https://www.lefigaro.fr/secteur/high-tech/en-estonie-une-intelligenceartificielle-va-rendre-des-decisions-de-justice-20190401, accesat 10.12.2021.

${ }^{21}$ [Online] la https://republica.ro/uberizarea-muncii-de-ce-munca-ar-ramane-ca-acum100-de-ani-8-ore-pe-zi-5-zile-pe-saptamana, accesat 10.12.2021. 
platformelor online de vânzări de tipul Amazon sau Emag, agenţiile de turism sunt ameninţate de platformele de tip booking.com sau Airbnb.com, iar televiziunea clasică are o problemă serioasă cu audienţa din cauza dezvoltării platformelor de tipul Tiktok, Netflix sau Youtube. Bineînţeles, exemplele pot continua. În acest context, ar fi cu totul nefiresc ca dreptul să nu intre sub umbrela fenomenului descris mai sus. În mod particular, contractul de asistenţă juridică încheiat între un avocat şi un client poate suferi modificări esenţiale. Din acest punct de vedere, Legea nr. 51/1995 privind organizarea şi exercitarea profesiei de avocat deţine unele reglementări care par în afara uberizării actuale. Există deja platforme care oferă servicii juridice ${ }^{22}$ online sau care intermediază legătura dintre client şi avocat $^{23}$, iar unele soft-uri pot înlocui sfaturile unui avocat prin folosirea de algoritmi bazaţi pe experienţe anterioare ${ }^{24}$. Christiane Féral-Schuhl ${ }^{25}$, fost preşedinte al Consiliului Naţional al Barourilor din Franţa, avocat în dreptul noilor tehnologii, susţine în volumul „Cyberdroit” că dezvoltarea platformelor online este un ajutor real pentru profesie: „avocatul, la fel ca un medic, este singurul autorizat să depună un diagnostic legal. $\mathrm{Cu}$ toate acestea, trebuie să folosească aceste noi instrumente pentru a răspunde mai bine nevoilor justiţiabililor şi pentru a se adapta la noile lor constrângeri în societatea digitală. La fel ca medicul, aceste instrumente îi vor permite să-şi gestioneze altfel profesia, dar subliniind valoarea adăugată care este de neînlocuit: diagnosticul. Unii văd aceste schimbări ca pe o ameninţare pentru avocat. De altfel, dacă expresia uberizare este recentă, procesul a început imediat ce a apărut internetul. Secretarii caselor de avocatură au fost primele victime, unele dintre sarcinile lor fiind „absorbite” treptat de avocaţi. Prin urmare, implementarea serviciilor juridice online este o extensie a unui proces de lungă durată" ${ }^{\prime 26}$.

Astăzi, raportat la toate cele menţionate mai sus, poate fi de neînţeles prevederea regăsită în conţinutul art. 245 din Statutul profesiei de avocat cu privire la faptul că firma unui cabinet de avocatură trebuie să aibă dimensiunile maxime de 40 X $60 \mathrm{~cm}$, să aibă o amplasare strictă sau că trebuie să cuprindă anumite menţiuni gravate în mod obligatoriu pe un suport metalic ${ }^{27}$. Această prevedere are

22 [Online] la https://www.acjsfb.ro/2021/02/16/parteneriatul-dintre-inteligentaartificiala-si-profesiile-juridice-un-salt-urias-pentru-omenire/, accesat 10.12.2021.

23 [Online] la https://www.zf.ro/business-hi-tech/platforma-avocatura-com-95-dintreclienti-prefera-consultanta-video-18925207, accesat 10.12.2021.

24 [Online] la https:/www.wolterskluwer.com/ro-ro/expert-insights/ai-sau-nu-ai-inavocatura, accesat 10.12.2021.

25 [Online] la https://www.cnb.avocat.fr/fr/christiane-feral-schuhl-presidente-du-cnb, accesat 10.12.2021.

${ }^{26}$ C. Féral-Schuhl, Cyberdroit 2020/2021 - 8e ed.: Le droit à l'épreuve de l'internet, Editura Praxis Dalloz, Paris, 2020.

${ }^{27}$ Articolul 245 din Statul profesiei de avocat Statutul profesiei de avocat din 3 decembrie 2011 (actualizat).

„(1) Firma trebuie să aibă dimensiunile maxime de $40 \times 60 \mathrm{~cm}$ şi va fi amplasată la intrarea imobilului şi/sau a spaţiului ocupat în care forma de exercitare a profesiei îşi are sediul profesional principal sau secundar ori biroul de lucru. 
legătură cu publicitatea în cadrul profesiei de avocat. Prin hotărârea nr. 195/11.09.2021 pentru modificarea şi completarea Statutului profesiei de avocat, adoptat prin Hotărârea Consiliului Uniunii Naţionale a Barourilor din România (UNBR) nr. 64/201128, publicată în Monitorul Oficial nr. 1055 din 4 noiembrie 2021, Uniunea Naţională a Barourilor din România a înţeles că acest tip de exprimare nu trebuie să-şi mai găsească locul în Statutul profesiei şi astfel, art. 245, menţionat anterior, a fost abrogat. În schimb, conţinutul art. 245 se regăseşte la punctul 6 din Ghidul de bune practici privind publicitatea avocatului şi a formelor de exercitare a profesiei, îmbrăcând forma unei recomandări. În concret, acest Ghid preia aproape integral tot ceea ce se regăsea la secţiunea privind publicitatea din statutul profesiei de avocat. Articolele 244-250 care privesc modul în care avocatul poate să-şi facă publicitate, dar mai ales interdicţiile cu privire la acest aspect, au fost abrogate cu totul odată cu intrarea în vigoare a Hotărârii nr. 195/11.09.2021. Deşi majoritatea restricţiilor privind publicitatea avocatului au fost mutate din statut în Ghidul elaborat de UNBR, interdicţia care se regăsea în conţinutul art. 244, alin. (2), lit. b ${ }^{29}$ nu a mai fost preluată în Ghidul de bune practici. Norma menţionată interzicea în mod expres acordarea de consultaţii juridice pe orice suport material sau prin orice mijloc de comunicare în masă, cu excepţia rubricilor juridice din diverse publicaţii.

În mod evident, o platformă informatică la care are acces un număr nelimitat de utilizatori este un mijloc de comunicare în masă şi astfel, se poate înţelege cu uşurinţă că practica avocaţilor care ofereau consultanţă juridică pe Tik-tok sau prin postări de tip live pe reţelele de socializare era interzisă. Această interdicţie a fost radiată pur şi simplu din statut şi nepreluată în Ghidul menţionat mai sus. În acest context, intervine o întrebare firească: în acest moment, poate avocatul să acorde consultanţă juridică pe reţelele de socializare ca şi cum s-ar afla pe o scenă de spectacol, iar utilizatorii ar dori răspunsuri la problemele lor juridice? Acest tip de retorică va naşte cu siguranţă polemici şi tensiuni în interiorul profesiei. Articolul care interzicea în mod expres acest fapt a fost abrogat, fapt care oferă un răspuns pozitiv la întrebarea anterioară. În schimb, rămâne în discuţie contractul de asistenţă juridică, forma în care trebuie încheiat, limitele de acţiune şi conţinutul acestuia. Articolul $108^{30}$ din Statutul profesiei, regăsit la secţiunea privind relaţia

(2) Firma cuprinde menţiunile prevăzute în anexa nr. XXII, gravate pe suport metalic”.

28 [Online] la http://legislatie.just.ro/Public/DetaliiDocument/247907, accesat 10.12.2021.

29 „(2) Nu este permisă utilizarea următoarelor forme de publicitate:

b) acordarea de consultații și/sau redactarea de acte juridice, realizate pe orice suport material, precum și prin orice alt mijloc de comunicare în masă, inclusiv prin emisiuni radiofonice sau televizate, cu excepția publicațiilor care conțin o rubrică de consultanță juridică;”.

${ }^{30}$ Articolul 108

„(1) Dreptul avocatului de a asista, a reprezenta ori a exercita orice alte activități specifice profesiei se naște din contractul de asistență juridică, încheiat în formă scrisă între avocat și client ori mandatarul acestuia.

(2) Forma, conținutul și efectele contractului de asistență juridică sunt stabilite prin prezentul statut. 
dintre avocat şi client, arată destul de clar că avocatul nu poate acorda asistenţă juridică fără existenţa unui contract de asistenţă juridică încheiat în formă scrisă. Art. 121 alin. 5 din Statutul profesiei permite încheierea contractului de asistenţă juridică în formă verbală, doar sub rezerva redactării contractului în forma scrisă în cel mai scurt timp. În acelaşi timp, potrivit art. 121 alin. (1), contractul de asistenţă juridică dobândeşte dată certă la momentul în care este înregistrat în registrul de evidenţă a contractelor, contractul fiind unicul mijloc de probă al raporturilor dintre client şi avocat (art. 122, alin. 7).

Protecţia oferită de contractul de asistenţă juridică trebuie să fie reciprocă ambelor părţi semnatare în sensul că, de exemplu, avocatul trebuie să-şi definească limitele mandatului şi să-şi monetizeze prestaţia, iar clientul trebuie să aibă un mijloc de protecţie împotriva unor eventuale sfaturi greşite din partea avocatului, nefiind valabilă asigurarea profesională în contextul unor consultaţii juridice pe internet, în public, fără existenţa unui contract. Practic, condiţia încheierii unui contract de asistenţă juridică îl împiedică pe avocat să poată acorda asistenţă juridică prin intermediul rețelelor de socializare sau a aplicaţiilor informatice care permit accesul unui număr nelimitat de utilizatori. În schimb, acordarea unor sfaturi juridice generale, nepersonalizate, poate reprezenta o formă de atragere a unor eventuali clienţi. Aparent este un tip de publicitate permisă de Statutul profesiei, deşi ar putea exista interpretări privind interzicerea acesteia dacă este asimilată unor forme de publicitate mascată ${ }^{31}$.

Lipsa de armonie între reglementările specifice profesiei de avocat şi evoluţia platformelor informatice de tipul Uber a fost oarecum corectată prin Hotărârea nr. 195/11.09.2021 a UNBR în sensul că a fost elaborat pe lângă Ghidul de bune practici şi Ghidul privind utilizarea platformelor online de către avocaţi. Acest ghid acoperă o necesitate a pieţei juridice, platformele online de intermediere a serviciilor avocaţilor existau, dar nu erau reglementate. În România, acest ghid a apărut pe fondul crizei sanitare generate de Covid-19, dar şi ca urmare a Ghidului privind utilizarea platformelor online ${ }^{32}$, elaborat de către Consiliul Barourilor Europene în iunie 2018. Permisiunea de a acorda consultanţă juridică prin intermediul platformelor online trebuie asimilată în mod obligatoriu cu posibilitatea mai facilă de a contracta, de a încheia un contract de asistenţă juridică cu fiecare client în parte, iar nu cu posibilitatea avocatului de a acorda consultanţă juridică oricărui

(3) Avocatul nu poate acționa decât în limitele contractului încheiat cu clientul său, cu excepția cazurilor prevăzute de lege”.

${ }^{31}$ Art. 2.6 din Ghidul privind utilizarea platformelor online de către avocați: Publicitatea mascată constă în reprezentarea prin cuvinte sau imagini a serviciilor, numelui, mărcii ori activităților avocatului sau formelor de exercitare a profesiei, în cazul în care o astfel de reprezentare este destinată unor scopuri publicitare nedeclarate și poate induce în eroare publicul cu privire la natura sa. Astfel de reprezentări sunt considerate intenționate mai ales atunci când se fac în schimbul unei plăți sau al unei contraprestaţii.

32 [Online] la https://www.ccbe.eu/fileadmin/speciality_distribution/public/documents/ DEONTOLOGY/DEON_Guides_recommendations/EN_DEON_20180629_CCBE-Guide-onlawyers-use-of-online-legal-platforms.pdf, accesat 10.12.2021. 
utilizator de internet, oricum, în orice condiţii. În plus, art. 120 alin. (1) din Statutul profesiei interzice acordarea de consultanţă juridică fără ca anterior avocatul să verifice identitatea exactă a clientului său ori a persoanei care contractează în numele acestuia. Este imposibil de realizat acest lucru în momentul în care un avocat acordă asistenţă juridică simultan unui număr mare de abonaţi ai unei reţele de socializare. Prin intermediul unei platforme juridice este de asemenea o misiune dificilă. De exemplu, partea adversă într-un litigiu îşi face un cont fals şi cere consultanţă juridică avocatului. Poate comunicarea pe internet să ofere o astfel de protecţie şi să asigure independenţa avocatului? Răspunsul este discutabil, însă, fiecare platformă are specificul ei, modalităţi diferite de interacţiune între client şi avocat.

\section{Tipuri de platforme informatice specifice avocaturii}

Ghidul CCBE privind utilizarea platformelor online de către avocaţi publicat în iunie $2018^{33}$ şi introdus ca anexă la Statutul profesiei de avocat din România în noiembrie 2021 arată că există diferenţe destul de mari între platformele informatice destinate avocaturii.

\section{a. Platforme care conţin registre cu avocaţi}

Acest tip de site-uri oferă un registru destul de amplu cu avocaţii care se înscriu sau care sunt înscrişi pe platformă, de cele mai multe ori contra unei sume de bani. Platformele create de organele de conducere ale profesiei din ţările Europene sunt gratuite. Este vorba de site-uri de tipul www.find-a-lawer.com. Sunt inserate datele de identificare ale avocaţilor, cu specializarea fiecăruia, iar clienţii pot găsi avocatul potrivit în funcţie de anumite filtre prestabilite. De obicei, pe acest tip de site nu există interacţiune între avocat şi client, acesta din urmă având posibilitatea să îl contacteze în mod direct, nemijlocit. În dreptul european, aceste platforme sunt denumite ,anuare”, iar în dreptul anglo-saxon sunt descrise sub termenul „directoare”. Aceste registre sunt gratuite pentru avocaţi. De cele mai multe ori, aceştia sunt înscrişi acolo fără să-şi dorească în mod expres asta.

\section{b. Platformele de recomandare ale avocaţilor}

Acest tip de site asigură o conexiune cu dublu sens între avocaţi şi clienţi. Dacă în primul caz clienţii căutau avocatul potrivit prin inserarea unor filtre stabilite în funcţie de specializare, experienţă şi localizare, platformele de recomandare oferă şi posibilitatea avocaţilor de a găsi clienţi noi. De obicei, aceste platforme conţin mai multe informaţii despre avocaţii înscrişi, dar şi modalităţi tehnice prin care profesionistul să răspundă, să interacţioneze într-un timp foarte scurt cu utilizatorul care are nevoie de servicii juridice. Aceste site-uri reprezintă de multe ori un atac direct la etica şi deontologia profesională pentru că oferă clasamente şi comparaţii între avocaţi, fiind lipsite de transparenţă în ceea ce priveşte ordinea în care sunt selectaţi avocaţii care apar pe prima pagina. Există şi

33 [Online] la https://www.unbr.ro/ghidul-ccbe-privind-utilizarea-platformelor-onlinede-catre-avocati/, accesat 10.12.2021. 
Uberizarea dreptului - pericol sau oportunitate pentru profesiile juridice liberale?

un risc real în ceea ce priveşte manipularea opiniei publice având în vedere că sunt finanţate atât de reclamele generate de numărul cât mai mare de utilizatori, cât şi de abonamentul pe care îl plătesc avocaţii înscrişi.

\section{c. Platforme de întrebări şi răspunsuri în domeniul juridic}

Aceste site-uri sunt foarte populare în rândul utilizatorilor care vor să afle cât mai rapid opinia unui profesionist. Obiectivul acestor platforme nu este acela de a pune în legătură avocaţii cu clienţii pentru încheierea unor contracte de asistenţă juridică, ci doar pentru a-şi putea creşte traficul de internet şi, implicit, pentru a obţine mai mulţi bani din reclame. În acelaşi timp, pentru avocaţi pot reprezenta un punct de pornire într-o eventuală relaţie de colaborare cu un client. Practic, avocatul oferă clientului un răspuns incomplet la o anumită întrebare, iar pentru o consultanţă elaborată, clientul va trebui să semneze contractul. În cazul altor site-uri de acest tip, clienţii sunt cei care trebuie să achite un abonament lunar pentru a avea acces la comunitatea juridică şi a putea pune întrebări.

\section{d. Platformele de tip „robotlawyers”}

Aceste platforme informatice oferă răspunsuri prestabilite la întrebări juridice uzuale. Pun la dispoziţia utilizatorilor un serviciu bazat pe inteligenţa artificială care poate să iniţieze şi să întreţină o scurtă conversaţie juridică. Pentru că aceşti „roboţi de conversaţie” nu pot funcţiona ca un avocat adevărat, pot direcţiona utilizatorul către un avocat specializat în domeniul solicitat. Aceste platforme pot reprezenta o oportunitate pentru avocaţi având în vedere că pot înlocui personal uman care răspunde la întrebări uzuale şi nu necesită cunoştinţe de IT foarte solide.

\section{e. Platforme care oferă şabloane şi automatizări de documente}

Reprezintă un instrument modern de eficientizare a activităţii unui cabinet de avocatură. Acest tip de platformă este destinat în principal cabinetelor sau societăţilor de avocatură pentru a uşura activitatea internă. Pare mai degrabă un produs dezvoltat exclusiv de profesionişti în informatică decât de jurişti. Programul este capabil să construiască modele de contracte, sau să creeze documentaţii necesare funcţionării unei societăţi. În acelaşi timp, poate crea modele de formulare destinate unei activităţi curente: înregistrarea unor firme, redactarea statutului unei asociaţii, plângeri sau cereri către instanţele de judecată etc.

\section{Uberizarea avocaturii în context european}

În România, fenomenul uberizării avocaturii s-a produs destul de târziu faţă de alte ţări europene, fapt recunoscut inclusiv de organele de conducere ale profesiei ${ }^{34}$. După cum am explicat anterior, există încă destul de multe inconsecvenţe în legislaţia specifică avocaturii, care pot conduce la concluzii de tipul: „cererile online se depun la camera 4 de la etajul 2”. Această concluzie este întărită

34 [Online] la https://www.bursa.ro/dike-supliment-dedicat-activitatii-de-dreptavocatura-se-38171uberizeaza38187-la-fel-ca-restul-serviciilor-69849448, accesat 10.12.2021. 
inclusiv de faptul că acel Ghid de bune practici anexat Statutului oferă dreptul Consiliului Baroului să verifice conţinutul unui site deţinut de un avocat şi să elimine menţiunile care încalcă principiile esenţiale ale profesiei. Până la data publicării Hotărârii nr. 195/2021 în Monitorul Oficial şi simpla creare a unui site de prezentare a avocatului trebuia aprobată de Consiliul Baroului ${ }^{35}$.

Prima ţară din Uniunea Europeană care a deschis calea acestei uberizări a profesiei a fost Franţa. Consiliul Naţional al Barourilor a pus la dispoziţia utilizatorilor două platforme de tipul celor descrise mai sus (un registru cu avocaţiti şi un site de recomandare ${ }^{37}$ ). Cele două platforme care pot fi accesate încă din anul 2016 sunt administrate în mod direct de către Consiliu. Platforma de recomandare a avocaţilor are filtre multiple prin care se asigură un contact cât mai rapid cu avocatul. Clientul poate iniţia un apel telefonic direct din aplicaţie, poate stabili o întâlnire la birou, o întâlnire video sau poate doar să adreseze o întrebare.

Decizia de a liberaliza în această manieră piaţa avocaturii vine în contextul tehnologizării agresive, dar şi în contextul Hotărârii Curţii de Justiţie a Uniunii Europene (CJUE) din data de 15 ianuarie $2015^{38}$, prin care s-a stabilit că avocatul nu este doar un jurist veritabil, ci este un furnizor de servicii, iar clientul este un consumator. Această hotărâre a Curţii de Justiţie a produs un adevărat seism în domeniul juridic având în vedere că în interpretarea Directivei 93/13/CEE a Consiliului din 5 aprilie 1993 privind clauzele abuzive în contractele încheiate cu consumatorii ${ }^{39}$, contractul de asistenţă juridică încheiat între un avocat şi un client este considerat a fi încheiat între un „furnizor” şi „un consumator”. Practic, Curtea a oficializat caracterul pur comercial al contractului de asistenţă juridică prin faptul că este standardizat, conţinând clauze deja prestabilite de avocat sau de Statutul profesiei. După această decizie, fenomenul uberizării avocaturii a devenit tot mai intens.

În Italia, restricţiile privind publicitatea avocatului, prevăzute de Legea nr. 247 din 31.12.2012, publicată în Monitorul Oficial nr. 15 din 18 ianuarie 2013, sunt oarecum similare cu cele din România. Pe site-ul Consiliului Naţional al Barourilor din Italia este publicat un anuar/registru privind avocaţii, însă nu are alte filtre de căutare decât cele standard: nume, oraş şi specializare. Autorităţile din Italia nu au creat o platformă de tipul celei de recomandare, prin care clientul să poată interacţiona instant cu avocatul, uneori chiar prin sistem video. În schimb, există un număr foarte mare de astfel de platforme private, care oferă inclusiv clasamente

35 „(2) Conținutul și modul de prezentare a adresei de internet se avizează, în prealabil, de consiliul baroului și trebuie să respecte demnitatea și onoarea profesiei, precum și secretul profesional”.

36 [Online] la https://www.cnb.avocat.fr/fr/annuaire-des-avocats-de-france, accesat 10.12.2021.

37 [Online] la https://consultation.avocat.fr/, accesat 10.12.2021.

38 [Online] la https://eur-lex.europa.eu/legal-content/RO/TXT/?uri=CELEX\%3A62013 CJ0537, accesat 10.12.2021.

39 [Online] la https://eur-lex.europa.eu/legal-content/RO/LSU/?uri=celex:31993L0013, accesat 10.12.2021. 
între avocaţ̧i, ranking-uri, recomandări de la foşti clienţi, fenomenul luând amploare începând cu anul $2017^{40}$. Latura pur comercială a avocaturii în Italia pare a fi foarte dezvoltată având în vedere concurenţa mare din interiorul profesiei. Media este de 4,5 avocaţi la mia de locuitori ai Italiei ${ }^{41}$ (în zone precum Calabria, chiar 7 la mie), o cifră mult mai mare decât în alte ţări europene. Pentru comparaţie, în România, media calculată la numărul avocaţilor care profesează şi sunt înregistraţi de $\mathrm{UBNR}^{42}$ este de 1,15 avocaţi la mia de locuitori. O precizare importantă este aceea că în Italia există deja, începând cu anul $2018^{43}$, mai multe platforme online care pun avocaţii în legătură între ei, nu doar cu clienţii. Mai exact, există platforme care intermediază legătura între avocaţi pentru găsirea rapidă a unor colaboratori, pentru substituirea în dosare sau pentru redactarea unor documente juridice.

În Germania, Legea Federală a Avocaţilor ${ }^{44}$ permite utilizarea platformelor pentru interacţiunea dintre avocat şi client. Există inclusiv un Registru Naţional Oficial al Avocaţilor în care sunt trecute toate datele de contact ale avocaţilor, inclusiv filtre suplimentare legate de specializare sau titluri academice. În acelaşi timp, platformele private de tipul celor care recomandă avocaţi sunt foarte bine promovate în spaţiul virtual.

\section{Referinţe}

Dochy M., La dématérialisation des actes du procès civil, Volumul 202, pg. 3, Editura Dalloz, Paris, 2021

Féral-Schuhl C., Cyberdroit 2020/2021 - 8e ed.: Le droit à l'épreuve de l'internet, Editura Praxis Dalloz, Paris, 2020

Ferrand F., Mayer L., Guinchard S., Chainais C., Procédure civile : droit interne européen du procès civil, Editura Dalloz, colecţia Précis Dalloz, ediţia 34, Paris, 2018

Fricero N., Demande en justice et nouvelles technologies: aspects procéduraux, în Les avocats dans le monde numérique : qu'en est- il aujourd'hui ?, Procédures, nr. 10, 2014, dosar 47

Rocayaura C., Réflexions sur la dématérialisation de la procédure pénale, thèse, Montpellier 1,2013 , no 3

40 [Online] la https://www.altalex.com/documents/news/2017/07/24/servizi-legali-ilfenomeno-dei-marketplace-digitali, accesat 10.12.2021.

${ }^{41}$ [Online] la https://nuvola.corriere.it/2019/12/24/quale-futuro-per-gli-avvocati/, accesat 10.12.2021.

${ }^{42}$ [Online] la https://www.ifep.ro/Justice/Lawyers/LawyersPanel.aspx, accesat 10.12.2021.

${ }^{43}$ [Online] la https://www.laleggepertutti.it/236186_lawe-la-prima-piattaforma-onlineper-avvocati, accesat 10.12.2021.

${ }_{44}$ [Online] la https://www.brak.de/fuer-verbraucher/anwaltssuche/, accesat 10.12.2021. 
